$\xi=-1$

\title{
Restoration of bronze bushes by the method of surface plastic deformation
}

\author{
Shepelenko I.V ${ }^{1}$, Warouma Arifa ${ }^{2 *}$, Sherkun V.V. ${ }^{3}$ \\ ${ }^{I}$ Department of Agricultural Machinery Operating and Repair, National Technical University of Kirovograd, Ukraine \\ ${ }^{2}$ Department of Rural Engineering \& Water and Forests, Dan Dicko Dankoulodo University of Maradi, Niger \\ ${ }^{3}$ Department of Mechanic and Technology, Agro technological University of State Tavri, Ukraine \\ *Corresponding author E-mail:warouma@yahoo.com
}

\begin{abstract}
The restoration cost for agricultural machinery parts systematically influences on that of agricultural production. Hence the need to find the most effective and less expensive methods for repairing these parts. The bushes of the connecting rods of internal combustion engines are among the parts that wear out quickly and are made with expensive and deficient bronzes. The technical equipment used consists a worn out bushes of bronze treated by various methods, a vibro-rolling device, deformation software, a profilograph-profilometer, a microscope, and a machine of friction. In order to analyze the performance of the bushes of the connecting rods of internal combustion engines resulting from various treatments, the following parameters were determined: the height of the micro-relief elements, the absorption and the surface oil retention force, the optimum support surface, the wear and the wear intensity, the temperature of the friction area and the duration of the running-in period. The vibro-rolling followed by the deformation by broaching increases oil retention force from 1.8 to 2 times, and the wear resistance from 1.86 to 3.45 times as compared with the traditional technology. This new technology can be used for the restoration of the bushes of the connecting rods of internal combustion engines.
\end{abstract}

Keywords: Bushes; Vibro-Rolling; Reaming; Deforming Broaching; Wear.

\section{Introduction}

One of the ways for developing the agricultural machinery construction technology includes the improvement of existing methods and the development of new ones. Elaborating a new method of repairing parts is a creative activity and requires the use of a systematic approach, based on technology unit of design, production and use of machine construction products [1]. The restoration cost for agricultural machinery parts systematically influences on that of agricultural production. Hence the need to find the most effective and less expensive methods for repairing these parts. The bushes of the connecting rods of internal combustion engines are in the group of parts that wear out quickly and are made with expensive and deficient bronzes [2], [3], [4], and [5]. Considering these factors, the large number of rods in use, and the fact that during engines repairing in many repair industries, the worn-out rods are replaced by new ones, we can say that the problem of restorating bushes of connecting rods is timely. The small dimensions of the repair surfaces of the bushes (diameter of the order of 40 to $50 \mathrm{~mm}$, length 45 to $55 \mathrm{~mm}$ ), the nonsignificant radial allowable wear (less than $0.1 \mathrm{~mm}$ ) and the hard working conditions restrict the use of several methods well known to restore the interior surfaces of the bushes (Chornovil et al., 1996; Gorokhov, 1978; Matalin, 2011).

The restorations of the worn out inner surfaces by coating and plastic deformation method remain the existing methods of recovery of the bushes of the rods [8], [9], and [10]. For a nonsignificant wear, it seems desirable to use the methods of superficial plastic deformation (SPD), at the same time the modification of the size and the improvement of the treated surface quality. The intensity of the metal redistribution process due to the complexity of the relative movement of the working part and the deformation element (ball, diamond tip) is possible by the vibro-rolling method [11], [12]. Thus, it is transmitted to the tool or to the part, apart from the advancing movement, an oscillating movement ensuring the obtainment of a regular microrelief (RM) with the given parameters. To increase the bearing area of the restored surface by the vibro-rolling method, it is possible to use the high performance method (HPM) as a finishing operation [2], [13]. Thus, for the restoration of the inner surfaces of the bushes of connecting rods, the use of the combined method of treatment is more appropriate [14], [15].

This method takes into account the use of vibro-rolling for the reduction of internal dimensions and the subsequent deformation by broaching to obtain optimal support surface with a high oil absorption and a nominal size of the damaged orifice.

\section{Materials and methods}

\subsection{Materials}

The material used during the experiment is composed of:

- Worn out bronze bushes treated by vibro-rolling followed by broaching deformation (VRBD) (Fig.1),

- Worn out bronze bushes treated by reaming,

- Vibro-rolling device for the treatment of internal cylindrical surfaces,

- Deformation software for the treated surfaces by vibro- rolling,

- Profilograph-profiler "Talysurf-5" for the study of MR parameters, 
- Microscope tool 25-UIM for determining the height of the MR elements,

- Friction machine SMC-2 for the study of surface antifriction properties.



Fig. 1: Small End of the Connecting Rods with the Bushes Restored by the Vibro-Rolling Deformation Followed by Broaching Method.

\subsection{Method}

Experiments were carried out in 2015 in the laboratory of the Faculty of Operation and Repair of Agricultural Machinery of the National Technical University of Kirovograd (Ukraine).

The bushes of the connecting rods of internal combustion engines have undergone two types of treatment namely treatment by VRBD (proposed method) and treatment with reaming (traditional method).

For the treatment of internal cylindrical surfaces by the vibrorolling method, it was manufactured a device (Fig.2) in which the oscillation of the tool, and its rotation are done by a training device (machine 'training).

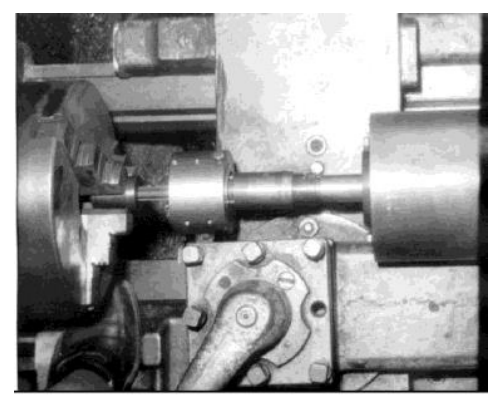

Fig. 2: Working Area of the Laboratory Device.

The proposed device consists of the leading part I, the oscillating part III and the multi beads roller II (Fig.3) mounted on a special lathe machine. The operating principle is that the multi balls roller performs a rotating movement and an alternative movement along the axis of the working part which is transmitted to an advancing movement of the tool [16].

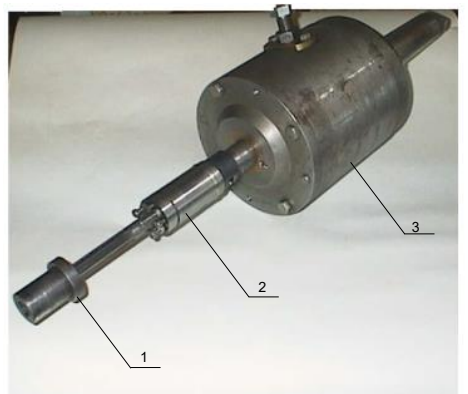

Fig. 3: Vibro-Rolling Device: 1 - Leading Part I; 2 - Beads Roller; 3 Oscillating Part.

In order to study the effect of broaching deformation on the formation of the MR contact surface after vibro-rolling, a deformation software was conceived (Figure 4).

The study of MR parameters before and after the VRBD was performed using a profilometer-profographe "Talysurf-5".

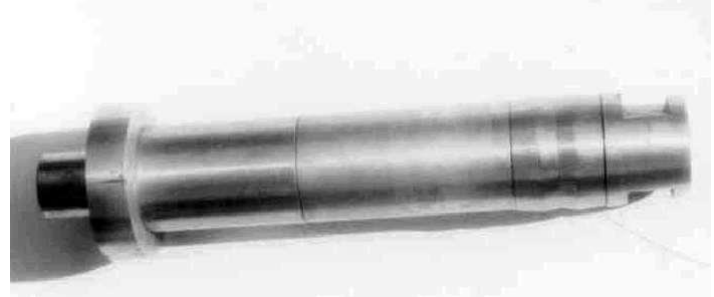

Fig. 4: Deformation Software for the Treated Surfaces by Vibro- Rolling.

The determation of the heights of the MR elements was carried out on the microscope tool UIM-25.

The surface oil absorption capacity was studied by filling the cavities of the microrelief by the polymer followed by the determination of its mass, which was used to determine the volume of the cavities and the specific oil absorption.

The running time was determined by the time taken from the beginning of the work until the period of reaching the friction limit state in the liquid. The antifriction properties of surfaces were studied on the SMC-2 friction machine according to the diagram "shaft - cylinder" with an estimate of the wear by the gravimetric method.

\section{Results and discussion}

\subsection{Results}

Figures 5 and 6 shows the dependence of the MR surface oil specific absorption based on vibro-rolling states.

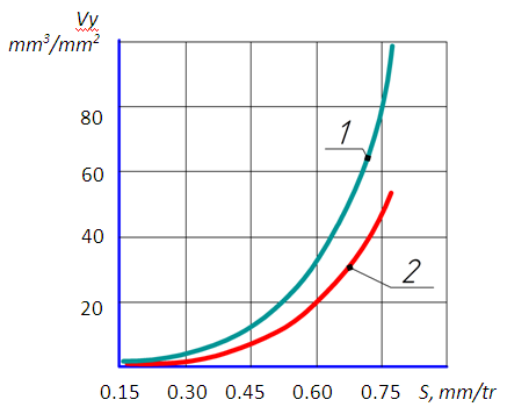

Fig. 5: Dependence of Surface Specific Oil Absorption Vy MR According to Advanced Movement $\mathrm{S}$ at Different Amplitudes of the Oscillations $\mathrm{L}$ of the Roller $(1-\mathrm{L}=5 \mathrm{~mm} ; 2-\mathrm{L}=10 \mathrm{~mm})$.

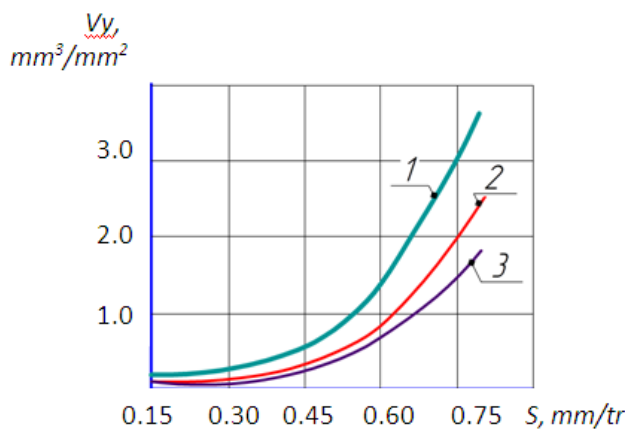

Fig. 6: Dependence of Surface Specific Oil Absorption Vy MR According to the Advanced Movement $\mathrm{S}$ during Different Diameters of the Ball Db(1 $-\mathrm{Db}=3.97 \mathrm{~mm} ; 2-\mathrm{Db}=5.80 \mathrm{~mm} ; 3-\mathrm{Db}=7.94 \mathrm{~mm}$ ).

Technological states of vibro-rolling process (advanced movement of the bushes (Fig 5 and 6), the diameter of the ball (Figure 6) and the amplitude of the oscillations (Figure 5) provide an increase of the specific oil absorption of the treated surface.

Figure 7 shows the dependencies of the contact surface treated by vibro-rolling according to the magnitude of the convergence with the coupling parts (curve 1) and the bearing surface of the treated 
surface by vibro-rolling according to the deformation of allowance(curve 2).

The optimal value of the bearing surface (Fig.7) is between 30 and $50 \%$ of the total area of friction (the optimal area of the bearing surface is shaded). The convergence of high values corresponding to the optimal value of the bearing surface (between 30 and 50\% of the total area of friction) are between 27 and $47 \mu \mathrm{m}$.

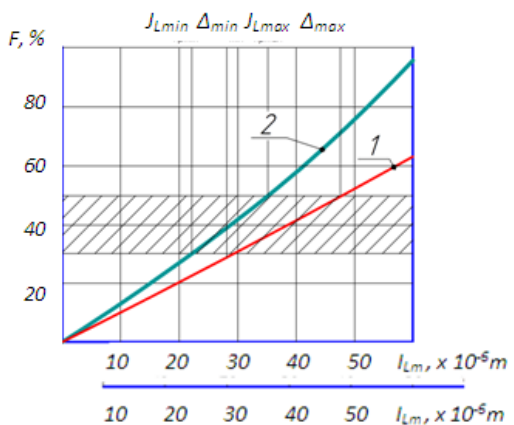

Fig. 7: Dependence of the Bearing Surface $F$ of the Treated Area by Vibro-Rolling According to the Magnitude of the Convergence Value $\Delta$ (1) and the Treated Surface by Vibro-Rolling after the Broaching Deformation Depending on the Allowance $\mathrm{J}_{\operatorname{lm}}(2)$.

Increasing the height of the MR element (Fig.8) contributes to the increase of the running-in period.



Fig. 8: Dependence of the Running-in Period T According to the Height $R$ of the MR Element after the Vibro-Rolling: Shaft: Tempered Steel 45; Untempered Steel 45. Bushes: 1, 2 - Br OCS 5-5-5.

Figure 9 shows that for low values of the contact surface (less than $30 \%$ ) and high values of the latter (over 50\%); the running time increases (curves 1 and 2).

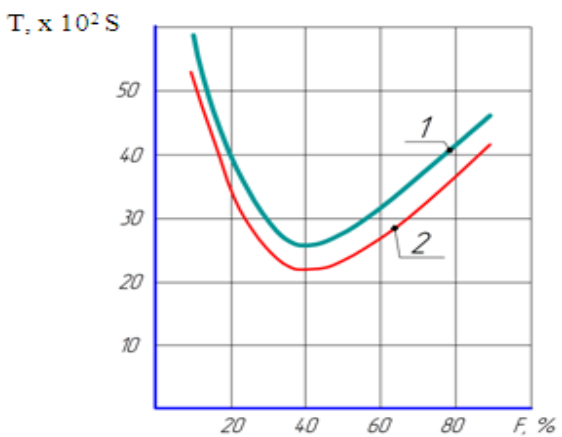

Fig. 9: Dependence of the Running-in Period T According to the Bearing Area $\mathrm{F}$ after by Broaching Deformation. Shaft: Tempered Steel 45; Untempered Steel 45; Bushes: 1, 2 - Br OCS 5-5-5.

The wear (Figure 10) and the coupling wear intensity (Fig.11, 12) depend on the final method of surface treatment. During the application of the MR by the vibro-rolling method and its subsequent deformation by broaching, the wear resistance increases suddenly (Figure 11, curve 2) during the wear " limit " (Figure 11) and during the wear "dry" (Figure 12).

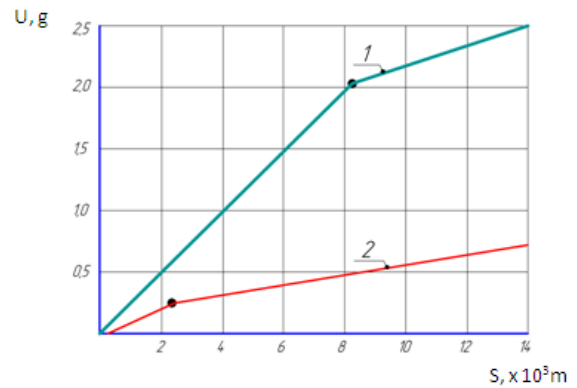

Fig. 10: Dependence of Wear $U$ of the Bushes According to the Friction Distance S: 1 - Reaming Treatment; 2 - Vibro-Rolling Treatment Followed by Broaching Deformation.

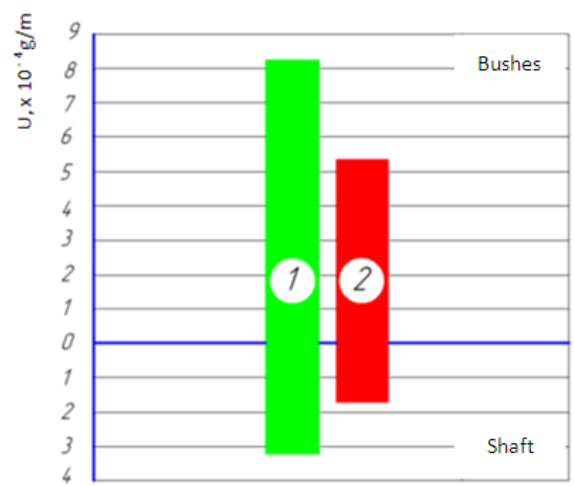

Fig. 11: Diagram of the Wear Intensity $U$ of the Coupling Parts during the Different Methods of Bushes Treatment (Wear Limit). 1- Reaming Treatment; 2- Vibro-Rolling Treatment Followed by Broaching Deformation.

Thus, figures 10, 11 and 12 show that the VRBD increases the wear resistance from 1.86 to 3.45 times in comparison with the traditional method.

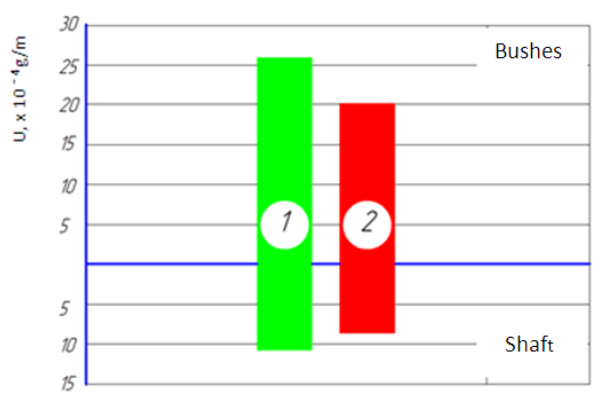

Fig.12: Diagram of the Wear Intensity U of the Coupling Parts at Various Methods for Surface Treatment of the Bushes (Dry Wear). 1 - Reaming Treatment; 2 - Vibro- Rolling Treatment Followed by Broaching Deformation.

The results of the retention force and the temperature at various treatment methods are shown in figures 13 and 14.

These figures show that during the VRBD, oil retention force is 1,8 to 2 times higher compared to the reaming treatment method.

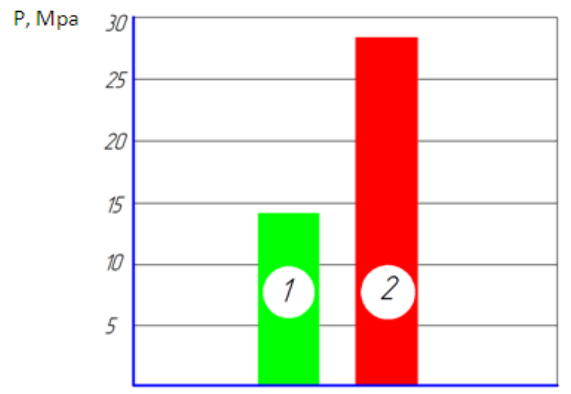

Fig. 13: Diagram of the Coupling Oil Retention Force $P$ during Various Treatment Methods. 1 - Reaming Treatment; 2 - Vibro- Rolling Treatment Followed by Broaching Deformation. 




Fig. 14: Temperature T Dependence of the Friction Area According to Oil Retention Forces P during Different Treatment Methods. 1 - Reaming Treatment; 2- Vibro- Rolling Treatment Followed by Broaching Deformation

\subsection{Discussion}

The volume of the evidements in the MR elements, in combination with their large radius and a significant activation of the surface of the metal brought in the cavities provide a sufficient oil absorption surface but also a good retention of lubricant on the treated surface.

However, during a sudden increase of oil absorption, the surface retention force is reduced, which negatively affects the operating properties of the treated parts. Therefore, for each working condition of mobile coupling parts, the presence of rational micro-relief parts of working surfaces is necessary.

The VRBD increases the oil retention force from 1.8 to 2 times, and the wear resistance from 1.86 to 3.45 times of the coupling "bushes-shaft" in comparison with the traditional technology.

These results are better than those of Gorokhov, (2008), where the oil retention during the VRBD is from 1.6 to 1.8 times superior and those of Kragelskii et al., (1998), where the wear resistance at the VRBD is from 1.45 to 2.75 times superior in comparison with the traditional technology.

The increase in wear resistance of the samples in bronze, in our view, can be explained by the regular discretion of the bearing surface, the presence of large radius of curvature of the MR elements, the decrease of the probability of the retention as well as the sudden increase of oil absorbing surfaces (during the wear limit).

Technological states of vibro-rolling namely the supply of the cylindrical sample, the diameter of the ball and the amplitude of oscillations provide the increase in the specific oil retention of the treated surface. Therefore, by varying these states, we can obtain the optimal volume of the cavities of the MR elements.

The optimal value of the bearing surface is between 30 and 50\% of the total area of friction. To obtain these values in order to reduce the running-in wear, it is necessary that the surface of broaching deformation and the surface treated by vibro-rolling is performed in the allowances order of $\mathrm{J}_{\mathrm{Lmin}}$ to $\mathrm{J}_{\mathrm{Lmax}}$. The optimal area when using the vibro-rolling can only be achieved at high values of convergence of about 27 to $47 \mu \mathrm{m}$. Therefore, to reduce the inside diameter; it is necessary when restoring the surface to take into account that the height of the MR element should exceed the value of the minimum allowable allowance during broaching deformation $\mathrm{I}_{\mathrm{Lmin}}$.

These results are confirmed by those of Dyachenko et al., (2003) where the optimal value of the bearing surface is between 30 and $55 \%$ and those of Kragelskii et al., (1998), where the convergence values are between 30 and $52 \mu \mathrm{m}$.

It was noticed that with the increase of the height of the MR element, the adjustment period increases, this is related to the decrease in the radius of curvature of the top of the MR element.

At low values of the support surface (less than 30\%) and large values of the latter (more than 50\%), the running-in period increases, which is due, in our view, to a high specific pressure that expels the oil fine layer of the contact area of the sample surfaces (for the first case) and a low surface roughness which poorly retains the lubricant in the area of friction (for the second case).

\section{Conclusions}

The adoption of the deforming trolling as a finishing operation ensures the obtainment of the optimal contact surface with increased oil absorption and a nominal dimension of the worn out bushes.

The creation at the finished processing step, of the optimal contact surface (30 to $50 \%$ of the friction surfaces) enables apart from the reduction of the running-in period to reduce the allowance of the coupling during the running-in wear.

The VRBD increases the oil retention force from 1.8 to 2 times, and the wear resistance of 1.86 to 3.45 times of the coupling "bushes-shaft" in comparison with the traditional technology.

The designed and manufactured device to the vibro-rolling enables to apply on the inner surface of bushes in bronze a regular microrelief. The VRBD improves the wear resistance in the friction conditions and can be used when restoring the bushes of the connecting rods of internal-combustion engines. The economic impact per year for 3.000 connecting rods repair program would be about 4.792 US Dollar.

\section{References}

[1] Suslov AG (2006), the improvement and the development of competing technologies ensuring higher quality of engineering products. Bulletin of the University Bryansk State Technical. N2, pp.24-29.

[2] Rosenberg AA, Ciechanow YA, Sheykyn SE (2005), Basis of consolidation of the surface layer during the broaching deformation. Hard materials, 4, pp. 56-68.

[3] Dyachenko PE, Tolmachev NN, Andreyev GA, Karpov TN, Real contact area of the friction surfaces, M : Academy of Sciences, (2003), 122 p.

[4] Kragelskii IV, Anisina VV, Friction, wear and lubrication, M: Construction of agricultural machinery, (1998), 750p.

[5] Papshev DD, Methods of parts treatment, M: Construction of agricultural machinery, (1968), $132 \mathrm{p}$.

[6] Chernovol MI, Nalyvayko VM, Solovuh EK, Solovuh AE, Shepelenko IV (1996), Increased sustainability of agricultural machinery by the contribution of electrolytic coatings based on copper. Construction, production and operating agricultural machines, Kirovograd: KYSM No 26, pp. 131-135.

[7] Gorokhov VA, Treatment of parts by plastic deformation, K: Technique. (2008), $192 \mathrm{p}$.

[8] Matalin AA, Technological methods for the improvement of the durability of the machine parts, K. Technique, (2011), 144 p.

[9] Yatsenko VK, Zaitsev GZ, Pritchenko VF, Ivschenko LI, The increase of the performance of the machine parts, $\mathrm{M}$ :. Construction of agricultural machinery, (1985), $232 \mathrm{p}$.

[10] Kempster MHA, Materials for Enqineers, London: The English Universities Press, (1975), 245 p.

[11] Schneider JG, Parts Performance characteristics with regular microreliefs, Construction of agricultural machinery, (1982), $248 \mathrm{p}$

[12] Murphy JA, Surface preparation and finishes for metals, New York: McGraw - Hill, (1971), 493 p.

[13] Posvyatenko EK, Paladyychuk YB (2000), Design of pins by vibration. Vibrations in the technics and technology, 2, pp. 57-61.

[14] Kragelsky IV Dobygin MN, Kombalov VS, Basic calculation of friction and wear, M: Construction of agricultural machinery. (1977), $526 \mathrm{p}$.

[15] Kropyvnuy VN, Shepelenko IV (2003), the increase of the quality of the friction surfaces by vibro-rolling method followed by broaching deformation. Journal of scientific work of the State Technical University Kirovograd, 12, pp.194-201.

[16] Chornovil MI, Shepelenko IV, Warouma Arifa (2011), Combined method of friction surfaces treatment. Journal of the scientific work of the National Technical University of Kirovograd. KNTU, 24 (2), pp.46- 49 . 